(C) 1996 Kluwer Academic Publishers. Printed in the Netherlands.

\title{
Comparative higher education studies: The perspective from the policy sciences
}

\author{
LEO GOEDEGEBUURE \& FRANS VAN VUGHT \\ Center for Higher Education Policy Studies, University of Twente, P.O. Box 217, 7500 AE \\ Enschede, The Netherlands
}

\begin{abstract}
The article explores the historical background of comparative policy studies. These studies are traced back to the comparative approaches in political science and public administration. Following a discussion on the methodological aspects of the comparative approach, an overview and assessment of a number of recent comparative policy studies in higher education is presented.
\end{abstract}

\section{Introduction}

Making comparisons among entities and units is one of the crucial aspects of scientific analysis. According to Swanson (1971, p.145) 'Thinking without comparison is unthinkable. And in absence of comparison, so is all scientific thought and scientific research.' This point of view is underlined by many other authors. The political scientist Almond (1966, p.878) for instance calls comparison, 'whether it be in the experiment, in the analysis of the results of quantitative surveys, or in the observation of process and behaviour in different contexts in the real world ... the very essence of the scientific method'. According to the sociologist Smelser (1976) all scientific methods are comparative, and the anthropologist Geertz (1983, p.233) has observed that 'it is through comparison that whatever heart we can get to, can actually be reached'.

While many social scientists would agree that virtually all social scientific methods are comparative in the broad sense of the word, the terms comparative method and comparative studies usually are reserved for a more specific category of research projects. However, the literature on comparative analysis offers no agreement on what the characteristics of these more specific studies should be. Comparative studies are defined as studies using comparable data from at least two societies (Armer 1973, p.49) or as a form of multilevel research (implying comparative analysis both within and across systems) (Przeworski and Teune 1970, pp.50-51). We would like to follow Ragin who states that neither a data category, nor a multilevel approach should 
be used to define comparative studies, simply because these definitions are too restrictive. 'What distinguishes comparative social science is its use of attributes of macrosocial units in explanatory statements' (Ragin 1987, p.5).

The comparative method goes back to the logical methods of John Stuart Mill. Mill (1843) suggested that next to the 'method of difference' (the experimental design), two 'methods of inductive inquiry' could be distinguished: the method of agreement and the indirect method of difference. We will come back to these methods later in this text. For now it suffices to realize that comparative studies in the social sciences have a remarkable history.

But although their history is impressive, it is only since World War II that these studies really have developed as a specific academic field. As we will describe below, this field since then has gone through periods of expansion and contraction. Recently, however, there appears to be a 'revival' of comparative studies, especially in the form of comparative policy studies.

This article first explores the historical background of comparative policy studies. It traces back these studies to the comparative approaches in political science and public administration. Secondly, the methodological aspects of the comparative approach are discussed. Finally, an overview is presented of the recent comparative policy studies in the field of higher education.

\section{A brief history of comparative studies}

The present-day comparative policy studies (in various fields, including higher education) can be seen as a more or less natural outgrowth of the developments in the fields of comparative politics and comparative public administration. Especially comparative public administration can be seen as the cradle of comparative policy studies. It in turn is closely linked to comparative politics, which can be described as the study of whole political systems (Diamant 1960).

\section{The early years}

The field of comparative politics has its origins before the second World War, but it is only since then that this field has really expanded. The changing world scene and especially the growing number and diversity of nation-states stimulated the comparative politics enormously. The aspirations were high. The common objectives were 'that the purview of comparative studies must be capable of including all existing nation-states, that comparison to be significant must be based on the collection and evaluation of political data in terms of definite hypotheses or theories, and that some alternative to a simple institutional basis for comparison must be found' (Heady 1991, p.7). 
Several efforts have been made to develop the theoretical base of the study of comparative politics. The two most influential conceptual frameworks have been functionalism and neo-institutionalism. The functionalist approach is for instance clearly found in the work of Almond. He suggested that all political systems have similar functions but that these functions are performed by different kinds of structures (Almond and Coleman 1960, p.11). Comparative studies would enable us to analyse these structures and to evaluate their advantages and disadvantages. The neo-institutionalist approach places an emphasis on the nation-state and its institutions. The state is seen as a concept to be distinguished from 'government' and involves the many actors and organizations related to the processes of politics and policy. An example of a neo-institutional approach to comparative politics is found in the work of Heper (1987), who develops a typology of categories of polity. By means of comparative studies actual political-administrative systems could be characterized using this typology.

According to Heady (1991) comparative public administration emerged in the tracks of comparative politics. He cites the well-known article by Robert Dahl in which it is argued that '.. as long as the study of public administration is not comparative, claims for a "science of public administration" sound rather hollow' (Dahl 1947, p.8). Dahl's words were clearly heard. During the first two decades after the end of World War II a growing number of universities offered courses in comparative public administration, and in 1960 the Comparative Administration Group (CAG), affiliated with the American Society for Public Administration, was established. Chairman of CAG became Fred W. Riggs. In this position and through his publications Riggs has had a major influence on the development of this field.

Comparative public administration has, since its early days, mainly been focused on the administrative subsystems of political systems. In their studies the researchers in this field tried to analyse the various administrative processes and to construct models that would allow further investigation of administrative systems. By the beginning of the 1960s Riggs identified three trends in comparative public administration: a shift from normative toward empirical approaches, a movement from 'idiografic' toward 'nomothetic' approaches and a shift toward an ecological basis for comparative studies (Riggs 1962).

The heyday of comparative public administration were the 1960s and the early 1970s. During those years there was ample financial support for comparative studies; there were special journals and publishers, and a vast amount of scholarly output. In retrospect this output can be characterized by three features (Heady 1991, pp.20-24): an instrumentalist orientation, the dominance of the theoretical concept of bureaucracy, and the search for a comprehensive 
theory. Regarding this last point, Jreisat (1975, p.667) notices that comparative public administration has put an emphasis on 'the level of grand theory in the sociological tradition'. And Fried (1990, p.318) underlines that the aspiration was to 'deduce from this theory the secrets of change - the means of hastening or altering the bureaucratic fate of nations'.

\section{Intellectual malaise}

Unfortunately, from the early 1970 s on, comparative public administration reached a phase of disappointment and lessened support. The large output apparently had not been able to build up an integrated and coherent paradigm. As Savage (1976. p.417) put it, in the early 1970s it appeared that comparative public administration 'started with no paradigm of its own and developed none'. Financial support for the work of CAG decreased; the Journal of Comparative Administration ceased publication (in 1974 it was merged into a new journal: Administration and Society); the interest of students for the field diminished; and CAG itself went out of existence in 1973 (Heady 1991, p.25-26).

Guy Peters provides some cynical characterizations of the decline of and the disappointment with comparative public administration, ${ }^{1}$ and identifies an 'intellectual malaise'. A point of view that is supported by authors like Jreisat (1975), Savage (1976), Sigelman (1976) and Springer (1976), who all conclude that by the second half of the 1970s comparative public administration lacks an integrative paradigm and has been unable to focus the many diverse studies on a theoretically interesting and practically useful set of topics.

Fried (1990, p.322) offers two sets of factors that might explain this failure of comparative public administration, 'one relating to the nature of the subject matter and the other relating to the nature of the knowledge industry concerned with that subject matter'. The problem with the subject matter is that the boundaries of the field are difficult to establish and relevant data are not always easy to find. At the same time, experts in the field of comparative public administration are limited in numbers, and funding agencies are less interested in sponsoring the creation of a universal theory than in funding action-oriented studies.

Let us briefly insert here that by the end of the 1970s the field of comparative education studies suffered from more or less the same disillusion. Also in this field did the search for a 'grand' theory by the second half of the 1970s lead to disappointment and decreasing support. In their overview of the field of 1986 Altbach and Kelly conclude that comparative education has gone through several phases. The origins of this field are found in four traditions: the tradition of the 'travellers' tales' (descriptions of educational practices in other countries); the tradition of 'lending and borrowing' (which aims at transferring 
practices from one country to another in the hopes of reforming education for the better); the tradition of 'historical/cultural studies' and the tradition of 'international understanding in general and education in particular' (Altbach and Kelly 1986, p.3-4).

They also indicate that in the 1960s a new tradition emerged that tried to build up a 'science of comparative education', emphasizing methodological approaches from the social sciences in general. However, as we already indicated, the 1970s brought a period of disillusion. In an article published in 1979, the then president of the Comparative and International Education Society, J. Farrell, described the state of the field as follows: 'There is a lack of cumulation in our findings; we have many interesting bits and pieces of information, but they seldom seem to relate to one another. We have little in the way of useful and concise theory; what pass for theory ordinarily are abstracted rhetorical "world views" ... unoperationalized and with little predictive power. Our research results are generally of little use to, and little used by, policy-makers.' (Farrell 1979 in Altbach and Kelly 1986, p.202). Similar litanies can be found in other articles (e.g. Anderson 1977; Halls 1977).

However, several authors argue that the 1980s have brought a new vitality to comparative education: 'The field in the 1980s has matured and has begun to arrive at a deeper understanding of the complexity of drawing relations between the meaning of education in today's world ... Comparative education in the 1980s is a healthy, intellectually viable field of study' (Altbach and Kelly 1986, pp.7-8). It is emphasized that this growing maturity of the field will have to be combined with a better understanding of the epistemological and methodological aspects of comparative analysis. According to Noah (1986, p.161) comparative analysis should be the approach which "by providing counterinstances, challenges us to refine our theories and test their validity against the reality of different societies'. Farrell (1986, p.207) underlines that the discovery that a relationship holds in a particular society is of little use 'unless we understand why the relationship holds, unless, that is, we have an explanation for it'. And Theisen and Adams (1990, p.278) indicate that comparative education 'is expected to meet the acknowledged standards for scientific research'.

\section{Revival}

It appears that since the second half of the 1980s a 'revival' of comparative analysis can be noticed (Fried 1990, p.338; Heady 1991, p.39). Although some authors claim that the field of comparative education 'has not yet gained the status of a fully established discipline, [that] there are legitimate doubts whether this status will be achieved at all, ... [and that] its content 
and scope ... are controversial' (Mitter 1993, p.1788), the place of this field is nevertheless established in modern research (Theisen and Adams 1990, pp.282, 283).

Certainly in comparative public administration a fundamental reflection is taking place which has resulted in a reappraisal of some of the basic notions in this field. Comparative public administration is now being seen as 'more than simply the accumulation of descriptive material about different countries' (Guy Peters 1988, p.3). It should pay attention to the fundamental aspects of the comparative method and can therefore be defined as all studies of administrative phenomena where the comparative method - in some guise - is explicitly employed (Goodsell 1981). We will come back to the characteristics of the comparative method further on in this article. Let us underline here that in comparative public administration the 'intellectual malaise' of the second half of the 1970s has directed the attention to the various aspects of the comparative method and that the methodological consciousness of the comparative analysts in this field appears to be growing. The will to bring the field to a higher level is clearly there. As Riggs (1991, p.473) himself recently has stated: '.. we need to develop frameworks and theories for the study of public administration ... Such a framework will not be idiographic, consisting only of descriptive information and case studies; rather it will be nomothetic, focusing on explanatory theories that account for the continuously changing properties and problems faced by governments as they seek to implement public policies'.

Riggs' statement points at one of the most promising new developments in the general field of comparative studies: the emergence of comparative policy studies. Heady (1991) mentions these studies as one of the interesting new perspectives in comparative analysis and Guy Peters claims that this 'subfield' has made greater progress than comparative public administration itself (Heady 1991, p.47; Guy Peters 1988, pp.9,12).

Comparative policy studies have emerged in the mid-1970s and have expanded enormously since then (Henderson 1981; Hancock 1983). Comparative public policy (as Heidenheimer c.s. call this field) is the study of 'how, why, and to what effect different governments pursue particular courses of action and inaction' (Heidenheimer, Hecclo and Adams 1990, p.3). As a newly emerging field of study, comparative public policy has kept a close relationship with the intellectual framework of twentieth-century social science in general and has reached a certain level of intellectual maturity which is expressed in the moving away from the search for single-factor, deterministic theories and the acceptance of the need to integrate diverse perspectives as wel as an increasing sensitivity to methodological problems. Presently comparative policy studies form their own specialized field, with their own 
professional associations, their own conferences and their own publication outlets.

Compared to the fields of comparative politics and comparative public administration, comparative policy studies are more restricted and - perhaps - in better circumstances to develop theoretical explanations. Guy Peters (1988, pp.12,188) argues that comparative policy studies were able 'to stamp out, or at least to imperil' comparative public administration because of the availability of convincing comparative indicators (like the level of government expenditure and various demographic indicators). At the same time, comparative policy studies were able to develop theoretical models that explain differences in policies across nations and to test these models empirically (Leichter 1979; Dierkes, Weiler and Berthoin Antal 1987; Heidenheimer, Heclo and Adams 1990).

The substantive fields in which comparative policy studies have been the most influential are first of all the sectors in which present-day governments play a key role in terms of allocation decisions (education, health, housing). Next to these sectors are the fields of economic policy (and the influence by governments on the overall performance of the economy) and social policy (including taxation policies and income maintenance policies). Following these are the policy sectors of urban planning, environmental planning, transportation, etc. In all these sectors comparative studies appear to be increasing (Dierkes, Weiler and Berthoin Antal 1987; Heiden-heimer, Heclo and Adams 1990). And in several of these sectors specialized research groups have started to undertake highly focused comparative studies.

The sector of higher education is an area in which specialized and focused comparative policy analysis only recently has been developed. Studies of the systems of other nations certainly have a certain tradition. In their well-known bibliography of international higher education of 1985 Altbach and Kelly present 6901 entries. However, it is noticed that most studies deal with only one country or even a single institution: ' ... specifically comparative and crossnational research and analysis is rare' (Altbach 1985, p.4). Comparative policy studies in higher education appear to be even more rare. Although Altbach and Kelly give over 450 entries in their category 'policy and planning', comparative policy studies are hardly found.

Like in several other specialized policy sectors, also in higher education the comparative research orientation appears to combine two types of studies. On the one hand there are the studies that address the 'how, why and what' of governmental higher education policies. On the other hand, this field of study shows an increasing number of studies oriented at exploring and comparing the specific characteristics of higher education systems and higher education 
institutions, in the hope that by doing so the comparative analyses will gain in strength.

\section{The comparative method}

Generally speaking, the comparative method in social science research can be defined as a method of analysis that focuses on several objects of study in order to identify similarities and differences. Lane calls this the thin definition of comparative social science research. The thick definition (which he prefers) 'argues that comparative social inquiry involves the analysis of properties of various kinds of spatial units: countries, states, societies and sub-national government entities' (Lane 1990, p.188). According to him the comparative method aims at the analysis of the genus and the differentia specifica of a social system (ibid, p.196), which is a position very similar to Ragin's (1987) who claims that the comparative method in the social sciences is distinguished by its use of attributes of macrosocial units in explanatory statements. As we indicated before, we accept the thick definition of the comparative method in social science research. Like Lane and Ragin, we take the position that in comparative social studies macrosocial units are essential to the explanations that can be presented. These units, we will assume, are all kinds of social entities beyond the behaviour and the opinions of individuals.

As an example of such an explanation in comparative research, consider the relationship between governmental strategies and innovations in higher education curricula. Here, it is assumed that the governmental strategy of "selfregulation' is more successfull in creating innovations in higher education curricula than the governmental strategy of 'rational planning and control' (Van Vught 1989). This statement implies that in the higher education systems of specific countries, governmental strategies can be identified according to the distinction between the two strategies mentioned, and that in these systems there is a strong relationship between the type of governmental strategy and the level of innovations in curricula. Because the higher education systems are identifiable, a researcher could classify them as having a 'self-regulation' or a 'rational planning' strategy, and then examine the degree to which the systems with the 'self-regulation' strategy show a large number of innovations of curricula and the degree to which the systems with a strategy of 'rational planning and control' show a small number of innovations of curricula. If these two patterns can be established, then the general statement - in higher education systems there is a strong relationship between type of governmental strategy and the number of innovations of curricula - can be used to explain the particular situation of curriculum innovations in a higher education system of a specific country. 


\section{Problematic aspects}

Unfortunately, comparative social science research is rarely this simple. There are several problems that make comparative studies more problematic than the example indicates.

First of all there is the problem of equivalence, which can be described as the need to have confidence 'that the components and their properties being compared are the "same", or indicate something equivalent' (Teune 1990, p.54). The problem of equivalence is, of course, the problem whether 'something' compared in different countries or systems is in fact the same in its significance. The problem of equivalence cannot easily be solved and probably has no perfect solution: '... the search for its minimalization must lie in the comparison of countries in which the cultural contexts surrounding the "something" to be compared are as similar as possible' (Etzioni-Halevy 1990, p.118).

A second problem relates to the number of macrosocial cases that actually can be compared in a study. This number of cases is often limited by empirical constraints which can create doubts about representation and validity. 'Even the investigator who claims that he or she is interested in all societies, and defines societies as all contemporary nation-states, encounters serious statistical problems if a quantitative analysis of these cases is attempted. A seemingly large set of more than one hundred nation-states can be reduced by half if there are problems with missing data. Often, the remaining cases are not representative of the original hundred-plus nation-states, much less of all societies' (Ragin 1987, p.10).

Related to the problem of cases not being representative, is the problem that the assumption has to be used that macrosocial units are significant variance reducers (Teune 1990, p.44), meaning that the variance within these units is less than among them. Often this is not the case and the conclusion has to be drawn that there is greater variance within than among units. The solution for these problems can only be found in the theoretical justification of the cases in a study. Theoretical justifications may also reduce the number of relevant cases. Ragin (1987, p.10) rightly claims that 'the greater the theoretical specifity, the smaller the number of cases relevant to the investigation'. When a theoretical argumentation for selecting specific cases can be offered, the problems of representation (and of a limited number of cases) and of internal variance may largely be reduced.

Theoretical justification also offers a possible solution for the problem of a theoretical leap. This refers to making connections between observations within a country and the country as a system. It is the problem of claiming that an observation regarding a specific aspect of a macrosocial unit allows a general statement about that unit itself. The solution which may be offered 
by theoretical argumentation is the provision of a 'macrotheoretical context within which different types of systems, even those radically different, can be compared' (Teune 1990, p.49).

The last problem regularly mentioned in the literature on comparative analysis is Galton's problem. This problem was first raised by the statistician Galton during a meeting of the Royal Anthropological Institute in 1889 (Scheuch 1990, p.28) and concerns the question how much of the characteristics of a specific culture is due to its own autonomous dynamics and how much to diffusion from other cultures. Lijphart $(1975, \mathrm{p} .171)$ formulates the problem in more general terms: 'Galton's problem is that an empirical relationship found in several societies may be a true causal link, but may also be the result of historical learning; the linked characteristics may simply have been diffused together'. The problem can be interpreted as the lack of the independence of cases. If the cases in a study are not independent, the observations cannot help us in trying to formulate conclusions. The solution to this problem obviously is to try to make sure that the cases are independent, and to try to present an argumentation why diffusion or learning processes are not likely to be relevant. Here a relatively small number of cases is an advantage, because a small number of cases allows for more attention to details and a more thorough analysis of possible interdependencies between cases.

\section{The experimental model}

The ideal comparative research design is identical in structure to the experimental model. When a researcher sets up an experiment, he or she compares the experimental group (which is subject to an experimental treatment) with the control group (which does not receive the treatment). The two groups are identical. The only difference is that the experimental group does get the treatment which is not given to the control group. So, only one factor is allowed to vary between the two groups: the treatment. All other factors are held constant or are randomized. When it appears that significant posttreatment differences between the two groups appear, these are assumed to be caused by the treatment variable (Cook and Campbell 1979).

The methodological power, directness and simplicity of the experimental model offer a great attractiveness, also in the social sciences. However, there are several reasons why this model is not often used. Basicly these reasons are all related to the ways causation is assumed to operate in social reality. In social life an outcome or effect rarely has a single cause. Also, causes usually do not work in isolation. They rather are combined into sets of multiple and conjunctural causes, involving different combinations of causal conditions. Thirdly, the various relevant conditions may have different effects on the operation of specific (sets of) causes in different contexts. It may be point- 
ed out that the experimental model offers the possibility to assess multiple conjunctural causation (Ragin 1987, p.28). However, the experimental model cannot be applied when the conditions regarding the treatment variable and the experimental and control groups cannot be manipulated. In these circumstances we are forced to work with methods that are not as powerful as the experimental model, but that try to approximate this model as closely as possible. Also in comparative analysis, we should strive for methodological approaches that offer a type of comparison which is a close approximation to the experimental model. To explore this issue we turn to the classical work of John Stuart Mill.

\section{Mill's methods}

The methodological approaches used in comparative studies are all related to John Stuart Mill's presentation of canons of experimental inquiry. In his A System of Logic: Ratiocinative and Inductive (1843) Mill offers a set of research strategies for making empirical generalizations. For comparative analysis two of Mill's methods are of particular relevance: the method of agreement and the indirect method of difference.

The method of agreement is the simplest and most straight-forward of Mill's methods. Simply stated, the method of agreement argues that if two or more instances of a phenomenon under study have only one of several possible causal circumstances in common, then the circumstance in which all the instances agree is the cause of the phenomenon. Essentially, the method of agreement is a search for patterns of invariance. All instances of a phenomenon are identified, and the investigator attempts to determine which of the possible causal variables is constant across all instances (Ragin 1987, pp.36-37). It appears that comparative social scientists sometimes prefer this method of agreement above other methods. Lijphart (1975) for instance argues that the comparative method should be similar to (what he calls) 'the comparable cases strategy'.

In the method of agreement a constant (e.g. innovations in higher education curricula) is explained with another constant (e.g. the existence of the governmental strategy of 'self-regulation'), at least if all cases that are being examined agree on only this cause. A crucial problem with this method is (as Mill already indicated) that it is unable to establish a necessary link between cause and effect. The two constants may both be related to a third factor (say, a decrease in public funds for higher education) and the observed relationship may be spurious. According to Mill only the experimental model (the 'method of difference') is able to definitely establish a causal relationship. A second problem regarding the method of agreement is its incapability to take multiple causation into account (Ragin 1987, p.38). Mill already cautioned 
against the liberal use of the method of agreement. He preferred the "method of difference' and when this experimental model is not feasible, he suggested to use the 'indirect method of difference'.

The indirect method of difference attempts to approximate the experimental model as closely as possible. This method consists of a double application of the method of agreement and of a phase in which competing explanations are rejected through paired comparisons. Let us explain this by presenting an example.

Suppose a researcher believes that the governmental strategy of 'selfregulation' causes a high level of innovativeness in higher education curricula. To investigate this, first our researcher identifies instances of high innovativeness in curricula to see whether they agree in the presence of the governmental strategy of 'self-regulation'. If so, then instances of the absence of high innovativeness in curricula are examined to see if they agree in the absence of the governmental strategy of 'self-regulation'. The presence and absence of the innovativeness in curricula is cross-tabulated against the presence and absence of the governmental strategy of 'self-regulation'. If the cases investigated show that the presence and absence of the governmental strategy are related to the presence and absence of innovativeness in curricula, the argument that the governmental strategy of 'self-regulation' is the cause of innovativenes in curricula is supported. Next comes the phase of rejecting competing explanations through paired comparison. In our example, if the cases showing both the governmental strategy and a high level of innovativeness of curricula also display a decrease of the public funds for higher education (a competing explanation), then we try to find at least some cases showing the absence of both the governmental strategy and a high level of innovativeness in curricula but displaying a decrease of public funds for higher education. If this pattern can be established our researcher can reject the decrease of public funds as a possible alternative explanation. If all (or at least many) competing explanations can be rejected in this sense, the indirect method of difference approximates the method of difference (the experimental model).

Although the indirect method of difference is preferable to the method of agreement, it nevertheless also is incapable to account for multiple conjunctural causation. The paired comparison of a positive with a negative instance cannot establish a more complicated pattern of causation (Ragin 1987, p.41).

Ragin underlines that 'the major point of contrast between the indirect method of difference and the method of agreement is that the indirect method uses negative cases to reinforce conclusions drawn from positive cases. Generally, the indirect method is preferred to the method of agreement, but in some types of investigation the set of negative cases is ill-defined ... The 
examination of negative cases presupposes a theory allowing the investigator to identify the set of observations that embraces possible instances of the phenomenon of interest' (Ragin 1987, p.41). Once more it becomes clear that theoretical specification is essential to undertake a causal comparative analysis. The theory will have to guide us in exploring the effects of possible competing variables. Without theoretical guides we do not know where to look for competing explanations. Actually, without theoretical guides we are unable to establish a hypothesis about a cause - effect relationship in the first place.

Lijphart suggests that one of the solutions to the "problem of many variables and a small number of cases' - according to him the crucial problem in comparative studies - is to 'select comparable cases for analysis and to achieve a large measure of control as a result of their comparability' (Lijphart 1975, p.163). Based on this point of view, he states his preference for the 'most similar systems' design (Przeworski and Teune 1970, p.32), also called by him 'the comparable cases strategy' (Lijphart 1975, p.164). Following Mill and Ragin, it seems to us that in stead of only a search for comparable (or similar) systems, the analysis of differences - and especially of competing explanations - is essential for comparative studies. The indirect method of difference is indeed to be preferred over the method of agreement.

\section{The practice of comparative research}

In the practice of comparative research, the various methodological aspects that have just been discussed appear to play only a minor role. In comparative studies methodological questions are not often raised and methodological choices remain implicit. According to Oyen (1990) four different groups of comparative researchers can be identified. One group - the purists - believes that conducting comparative research is no different from any other kind of social science research, and that no special discussion on comparative studies is needed. A second group - the ignorants - pursues its activities across national boundaries without giving a single thought to the comparative method. The third group of researchers - the totalists - are well aware of the many problems of doing comparative studies, but deliberately ignore them and go ahead trying to do the best they can. The fourth group of researchers - the comparativists - acknowledge the points of view held by the purists and the totalists, but argue that in order to advance our knowlegde about cross-national research it is necessary to raise questions about the distinctive characteristics of comparative studies. Oyen thinks that in the practice of comparative studies much research 'is guided by the principles of least resistance or invitation by opportunity. One of the central research strategies, although not much discussed, seems to be the preference given to 
available data and methodological tools, and the leaning towards accessible networks and easy funding' (Oyen, 1990, p.15).

Unfortunately, also in comparative higher education studies the practical principles of 'least resistance' and 'invitation by opportunity' are clearly found. Aspects and problems of the comparative method appear to be completely ignored, as the following examples illustrate. Niblett and Butts brought a number of authors together without offering any indication what they were supposed to do to make their contributions comparable: 'One of the intentions in inviting contributions to this book was to give individuals a chance to tell at first hand of pioneering work within their own colleges or universities and to point out its significance' (Niblett and Butts 1972, preface). Seabury appeares to be astonished to find that the conference papers he edited address similar issues. It apparently did not occur to him that the conference may have provided an implicit conceptual framework that could have been made explicit in the volume: 'In editing these [conference papers], I have ... been struck with the remarkable degree of commonality of issues and problems which cut across national and even continental divides' (Seabury 1975, p.VII). Eurich frankly admits that the principle of 'invitation by opportunity' played a major role in his comparative country study: 'The 12 countries [in this study] may seem an odd lot ... They were not selected with carefully defined criteria in mind; in fact they simply responded to an invitation and had leadership interested in participating' (Eurich 1981, p.vii). And Ben-David presents a very limited motivation for the choice of country-cases in his study: 'The [four] systems to be discussed in this book ... are not just an arbitrary collection, but are the central part of the world system' (Ben-David 1977, p.5).

Of course, many higher education researchers involved in comparative studies are well aware of the problems regarding the comparative method. In the next section we will discuss several higher education policy studies in which the comparative method plays a major role. In some of these studies the methodological problems regarding the comparative method are clearly addressed. In other studies these methodological aspects appear to have received less attention.

It may be pointed out that comparative higher education policy studies often are not undertaken to analyse causal relationships. As the discussion in the next section will show, comparative higher education policy studies may have various different functions. Comparative policy studies in the field of higher education appear to be undertaken to find, discuss and interpret diverse experiences in higher education systems in different countries. In some cases these studies are used to pinpoint patterns of constant association, and sometimes comparative studies appear to contribute to the development of 
theoretical frameworks. But a causal analysis in which variance is explained is not often found.

As we indicated before, a truly causal comparative study would have to begin with the specification of the hypothesis to be tested (and for this a theory from which the hypothesis can be deduced is indispensable). The next step would be an overview of possible competing explanations, which would be followed by a clear specification of the cases and of the variables to be analysed in these cases. In a causal comparative study the specification of both positive and negative cases is crucial. The theoretical framework would have to provide indications for such a specification; if no framework is available, a causal analysis cannot be performed.

In higher education studies, as in many other fields of the social sciences, theoretical frameworks that might be used for causal comparative studies hardly exist. According to Nowak $(1989$, p.40) the state of the art in social theory is such that empirical analysis of hypotheses is 'difficult or even impossible'. It should not be surprising then that in higher education studies the number of causal analyses is very limited. We nevertheless have the task to try to increase this number. One of the major challenges in the field of comparative higher education studies is to design and implement a theoretically based causal analysis. Higher education researchers should accept the challenge recently formulated by Albritton (1994, p.74): 'to build, and then to integrate, "islands of theory", necessary for understanding the complexities and dynamics of policy systems across nations and over time.'

\section{Comparative higher education policy studies}

\section{A selection}

In an insightful chapter on the comparative effectiveness of higher education systems, Clark Kerr (1978, p.157) opens by stating that '[A]ny current consideration of the comparative effectiveness of systems of higher education is bound to end in failure, but it may be an instructive failure'. Whether the same can be said about the 'effectiveness' of comparative policy research in higher education remains to be seen, but it is instructive to learn that in 1978 'higher education is more often described than evaluated. We know more about its history, its structure, its governance, its human composition, its instructional content than we know about its consequences. Higher education may seek the truth but largely ignores even the measurable consequences of that search' (ibid, p.158). The question we pose in this last section is to what extent this situation has ameliorated over the last decennium and what means and 
methods now appear to prevail in the area of comparative higher education research.

Our attempt is not to provide an exhaustive overview on comparative studies, neither in scope nor in history. Two comprehensive reviews exist to which the interested reader is referred (Altbach 1979; Altbach and Kelly 1985). For our purpose, we concentrate on the developments during the last ten years, which have been documented less systematically. Unfortunately, this implies that we are not able to address seminal comparative studies like Ashby's Universities: British, Indian, African, Ben-David's Centers of Learning: Britain, France, Germany, the United States, Clark's The Higher Education System, Daalder and Shils' Universities, Politicians and Bureaucrats, Flexner's Universities: American, English, German, and Rashdall's The Universities of Europe in the Middle Ages; studies that each in their own right and with different emphases can be considered hallmarks in the development of comparative higher education studies. It also means that we cannot adequately discuss the pioneering activities of organizations like the International Council for Educational Development (ICED) or the International Association of Universities (IAU). A further limitation, again due to limits of space, is our concentration on published books, monographs and studies with the exclusion of articles, special issues of journals, conference papers, and the like. This, nevertheless, still leaves us with a very substantial body of literature from which to draw and which we cannot cover exhaustively. Therefore, we have arbitrarily but defendable selected those writings that from the perspective of comparative higher education policy studies - after all the focus of this article - appear to be the most characteristic examples of studies that portray or lack certain charateristics ascribed to comparative studies in the previous sections.

A categorization of comparative higher education studies

In attempting to create at least some order in the steadily increasing mass of comparative studies, we were struck by both the variety and similarities that appear to exist in these works. Variety in terms of the origins and scope of studies; similarities where the design and methodological rigor are concerned. We return to this last point in the next section. The immediate task at hand, however, rests with variety and scope.

An important distinction that can be made with respect to the more recent comparative studies relates to the impetus for research. In line with developments towards policy-driven and 'relevant' research, a steady growth in commissioned comparative research can be noted. The questions addressed in this type of study predominantly are information-oriented and descriptive. Clear examples of this are the Kaiser et al. (1991) study on public expenditure in the EU countries, the first part of the OECD study on the non-university sector 
(1991), the VSNU (1992) study on electrical engineering, and the Goedegebuure et al. (1993) study on Dutch engineering programmes in the European context. Substantial amounts of data are collected to answer specific policy questions on the situation in particular countries and thorough attempts the difficulties of which should not be underestimated - are made to present the data in comparable format and on the basis of comparable denominators. Through this, it becomes possible to identify cross-national trends and situations regarding the object of study. As such, this type of study provides valuable material for subsequent analysis and/or policy debate and formulation at both the supra-national and national level. They are comparative in the sense that a cross-national perspective is provided, but relatively light in their analytical content; an inherent feature as the project remits from the start do not provide for an explanatory focus but instead stresses inventarization. As such, they highlight the importance and the need for comparative policy research as good comparable data still are scarce.

Closely related to the above category are the evaluation projects commissioned in particular by the European Commission on the effectiveness of various European programmes. Prominent examples in this category are the series on the ERASMUS programme (e.g. Maiworm, Steube and Teichler 1991), and the project on study abroad programmes (Burn, Cerych and Smith 1990; Opper, Teichler and Carlson 1990). In this type of research the focus is not so much comparative in essence as by 'accident'. The fact that the policy to be evaluated is trans-national provides the comparative element, but the studies - based on their design - equally well could have been national evaluation studies. This is not to say that no account at all is taken of the comparative nature of the projects. For example, Burn et al (1990, p.31) argue that 'the more consistent use of a comparative approach, taking into consideration the different disciplines and systems of higher education as they influence expectations and arrangements for study abroad, is also an important element'. But one is left with the distinct impression that the primary focus and rationale is the specific policy under investigation, with the comparative component more or less a side-issue.

Where commissioned research quite frequently has a rather precise focus, this is less the case for studies that have been published as a result of conferences - which themselves might or might not have been sponsored by external agencies - or that are a collection of basically independent chapters. This type of studies perhaps is best identified as 'opportunity-driven'. Frequently, an attempt is made to suggest some form of coherence through a general introduction, but apart from covering a semi-common subject or topic, there is little to no direct comparison in these works. This task, ultimately, is left to the reader. As such, it is our impression that this type of 
work, aside from being informative in describing country-specific situations, has little direct bearing on comparative research. Although titles like 'Higher Education in International Perspective' (Morsy and Altbach 1993), 'Higher Education in Europe' (Gellert 1993) and 'From Dependence to Autonomy; The development of Asian universities' (Altbach and Selvaratnam 1989) suggest otherwise, they cannot be considered comparative in either specific focus or design.

Next in line we can discern those studies where an actual comparison is attempted by the editor(s) of the volume. Here we note a more strict structuring of the object of study through a more or less specified - and at times more explicit than others - common framework that guides countryspecific studies and provides the main points addressed in the constituting chapters. Typically, these works deal with exploring relatively new issues or underdeveloped areas of study such as the nature of the professoriate or graduate education (e.g. Clark 1987; 1993). Here, also, the academic interest surpasses the external interest. Through their exploratory designs these studies can best be categorized as the 'soft' form of comparative research: in stead of overall frameworks, ideosyncratic approaches coupled with a comparative conclusion prevail. As such, they clearly indicate the developmental stage in which most of comparative higher education studies still is, and that basically can be categorized as a search for frameworks for future thought and inquiry. In the words of Clark (1987, pp.397-398): 'If social analysis pursues worthy problems, then it will invest more fully in the effort to grasp the constancy and the change in the lives of academics and to base views ... on fact rather than fiction. To date, such inquiry has occurred only in fits and starts, with long pauses in between. Perhaps the collective effort mounted in this volume will direct reflection and research towards the day when we systematically will know much more about [the academic profession]'. That this is more than a cry in the dark has recently been illustrated by the comprehensive cross-national study on the academic profession initiated by the Carnegie Foundation (Boyer, Altbach and Whitelaw 1994). Exploratory works indeed can be followed by more systematic studies based on a common framework, even though here again the explanatory element remains below the surface and is lacking from the design at the outset.

Somewhat more analytical by design is a recent series of policy studies that again is characterized by the 'collective effort' but is based on an explicit framework with - in varying degree - some form of assumptions included and with, albeit careful, attempts at structured analyses and theory development. Examples of this category are the Van Vught et al. (1989) study on governmental strategies and innovations, the Neave and Van Vught $e t$ al. studies on the changing relationship between government and higher education in the 
developed (1991) and developing countries (1994), and the Goedegebuure $e t$ al. (1994) study on the relationship between steering, autonomy, quality and diversity.

In contrast to what we might label the 'collective effort' - even though in most cases the brunt of the comparative work obviously is borne by the editor(s) - there exist the individual attempts at comparative studies. Originating out of an academic interest in a particular subject, the comparative aspect is more prevalent throughout the study. Again, a wide variety in approaches can be identified. Teichler, for example, in his study on changing patterns of the higher education system, attempts to explain the shape of these systems through (a) the systematization of models used in describing the structure of systems and (b) the examination of the plausibility of major explanatory concepts prevailing in the literature (Teichler 1989, p.15). Even though his final conclusion might be somewhat disappointing in the sense that he notes 'a broad range of interesting approaches in analysing the structural developments of higher education [which] make us aware of specific aspects and provide interesting explanations of certain phenomena ... they provide partial views, explain only some cases in a plausible manner and tend to overestimate the explanatory power of the individual approach' (ibid, pp.107-108), his work shows the value of a systematic attempt at explaining a particular phenomenon through a more or less explicit framework. In somewhat different vein, Goedegebuure (1992) attempts a comparative explanation of merger processes in Australia and the Netherlands. And although explanation is not the major objective of his study on private sectors in higher education, Geiger employs an explicit research methodology wherein countries are selected on the basis of differences with respect to his typology: 'In essence then, this study proceeds in an a posteriori fashion, initially presenting cases of seven private sectors that conform to three basic structural types; next utilizing this material in part to break down and analyse the eighth and most complicated case [the USA]; and then drawing on this empirical base to construct a comparative exploration of significant dimensions of private higher education' (Geiger 1986, p.5). These studies and others such as Levy (1986) indicate the value of a structured design and a theory-based approach that, even though very partially at the moment, provide some first attempts at explanation rather than description and ad hoc analysis. Based on this limited and selected overview, what should we conclude about the state-of-the-art in comparative higher education studies?

\section{Conclusions}

Returning to the original question posed at the beginning of this section, we should ask to what extent comparative higher education has moved beyond 
the descriptive phase identified by Kerr. Here it appears that modesty must be the name of the game. For despite the common denominator 'comparative', comparisons very often are a second-order element at best. The vast majority of studies does not get beyond the descriptive stage, or at best does so only marginally. To be clear, analyses of course exist in e.g. individual chapters in 'collective efforts', but comparative analyses in line with our ideal type identified earlier are rare. And the combination with an explicit comparative and explanatory design appears rather unique. Nevertheless, be it perhaps in the 'fits and starts' manner noted earlier by Clark, methodology and explanation at times do appear central in some studies. Above, already some promising avenues and approaches have been identified that stand apart from the mass of descriptive studies. Another positive exception can be found in the work of Cerych and Sabatier (1986) in which an explicit framework for policy implementation analysis is used and the case-selection is based on notions of differences: 'The cases selected do not present a random sample ... but they do represent a sufficiently wide range of circumstances to make comparative findings significant' (Cerych and Sabatier 1986, p.5). They attempt to answer their questions regarding the goal-attainment of reforms and the reasons behind success and failure of these reforms by contrasting centralized and decentralized systems, single and multiple institutions reforms, and reforms directed at aspects of systems with reforms that endeavour global syster. change. The approach adopted allows for reasonable comparability of the outcomes of different reforms, for confrontation of assumptions with empirical realities, and for some generalization and further theorizing regarding the implementation of reforms in higher education.

As such, one of the most important implications of the Cerych and Sabatier study can well be the viability of applying frameworks developed outside of the direct 'field' of higher education research to the various phenomena that are part and parcel of higher education. Much of our work, in particular in the area we like to denote as 'comparative higher education' is remarkably inward oriented. Descriptions are used to validate further descriptions, analyses draw on these descriptions with reference to other higher education sources to substantiate perceived findings, and some even appear to be in search of a 'theory of higher education' or see this object of research as capable of developing a paradigm of its own. It is our firm conviction that higher education should not be seen as an individual discipline with its own theories. Despite all societal and individual importance it might have, it remains a phenomenon, and explanations for it cannot be found within itself. As such, it is a barren field. Therefore, explanations have to be found in existing disciplines, like history, sociology, economics, etc. This also implies that higher education studies are subject to the methodological requirements inherent in these disciplines 
in order to further our understanding of the phenomenon. This equally is the case for comparative higher education. But clarity of design and methodology still do not dominate the writings in comparative higher education studies. In this respect, Kerr's observation, unfortunately, still holds many truths.

\section{Note}

1. 'Comparative public administration has been viewed as a series of excursions into the exotica of world political systems with the intention of describing different administrative systems and, with any luck, of developing a repertoire of amusing anecdotes based on field work ... Comparative administration showed great promise during the 1960s and 1970s. That promise appears to have been unfulfilled ... it can be argued that the vast majority of the work in this field rather dully describes relatively minor elements of an administrative system in some country or makes predictable normative arguments about the virtues of development administration by those who stand to profit from more funding for it. The real intellectual fire appears to have gone out of the field.' (Guy Peters 1988, pp.8,181-182).

\section{References}

Almond, G.A. (1966). 'Political theory and political science', American Political Science Review 60, 4.

Almond, G.A., and Coleman, J.S. (eds) (1960). The Politics of the Developing Areas, Princeton N.J.: Princeton University Press.

Altbach, Ph.G. (1979). Comparative Higher Education: Research Trends and Bibliography, London: Mansell.

Altbach, Ph.G. (1985). Perspectives on comparative higher education: a survey of research and literature, in: Ph.G. Altbach and D.H. Kelly Higher Education in International Perspective, A Survey and Bibliography, London and New York: Mansell Publishing Limited.

Altbach, Ph.G. and Kelly, D.H. (1985). Higher Education in International Perspective, A Survey and Bibliography, London and New York: Mansell Publishing Limited.

Altbach, Ph.G. and Kelly, G.P. (eds) (1986). New Approaches to Comparative Education, Chicago: The University of Chicago Press.

Altbach, Ph.G. and Selvaratnam, V. (eds) (1989). From Dependence to Autonomy; The Development of Asian Universities, Dordrecht: Kluwer Academic Publishers.

Anderson, C.A. (1977). 'Comparative education over a quarter century: maturity and challenges', Comparative Education Review 21. (3). 405-418.

Armer, M. (1973). 'Methodological problems and possibilities in comprehensive research', in: M. Armer and A. Grimshaw (eds), Comparative Social Research, pp. 49-79. New York: Wiley.

Ben-David, J. (1977). Centers of Learning: Britain, France, Germany, United States, New York: McGraw-Hill Book Company.

Boyer, E.L., Altbach, Ph.G. and Whitelaw, M.J. (1994). The Academic Profession; An International Perspective, Princeton: The Carnegie Foundation for the Advancement of Teaching.

Burn, B.B., Cerych, L. and Smith, A. (eds) (1990). Study Abroad Programmes, London: Jessica Kingsley Publishers.

Cerych, L. and Sabatier, P. (1986). Great Expectations and Mixed Performance: The Implementation of Higher Education Reforms in Europe. Trentham: European Institute of Education and Social Policy and Trentham Books. 
Clark, B.R. (ed.) (1987). The Academic Profession; National, Disciplinary, and Institutional Settings, Berkeley: University of California Press.

Clark, B.R. (ed.) (1993). The Research Foundations of Graduate Education; Germany, Britain, France, United States, Japan, Berkeley: University of California Press.

Cook, Th. and Campbell, D. (1979). Quasi-Experimentation: Design and Analysis Issues for Field Settings, Boston: Houghton Mifflin.

Dahl, R.A. (1947), 'The science of public administration: three problems', Public Administration Review 7, (1), 1-11.

Diamant, A. (1960). 'The relevance of comparative politics to the study of comparative administration', Administrative Science Quarterly 5, (1), 87-112.

Dierkes, M., Weiler, H.N. and Berthoin Antal, A. (eds) (1987). Comparative Policy Research: Learning from Experience, New York: St. Martin's Press.

Etzioni-Halevy, E. (1990). 'Comparing semi-corruption among parliamentarians in Britain and Australia', in: E. Oyen (ed.), Comparative Methodology, Theory and Practice in International Social Research, London: Sage.

Eurich, N.(ed.) (1981). Systems of Higher Education in Twelve Countries, A Comparative View, New York: Praeger Publishers.

Farrell, J.P. (1979). 'The necessity of comparisons in the study of education: The salience of science and the problem of comparability', Comparative Education Review 23, (1), reprinted in: Ph.G. Altbach and G.P. Kelly (eds) (1986). New Approaches to Comparative Education, Chicago: The University of Chicago Press.

Fried, R.C. (1990). 'Comparative public administration: The search for theories', in: N.B. Lynn and A. Wildavsky (eds), Public Administration, the State of the Discipline, Chatham, N.J.: Chatham House Publishers, pp. 318-344.

Geertz, Cl. (1983). Local Knowledge, New York: Basic Books.

Geiger, R.L. (1986). Private Sectors in Higher Education; Structure, Function, and Change in Eight Countries, Ann Arbor: The University of Michigan Press.

Gellert, C. (ed.) (1993). Higher Education in Europe, London: Jessica Kingsley Publishers.

Goedegebuure, L.C.J. (1992). Mergers in Higher Education; A Comparative Perspective, Utrecht: Lemma.

Goedegebuure, L.C.J., Maassen, P.A.M., Phillips, T. and Smits, M. (1993). Dutch Engineering Programs in a European Context, vol. 1, Zoetermeer, NL: Ministry of Education and Science.

Goedegebuure, L.C.J., Kaiser, F., Maassen, P.A.M., Meek, V.L., van Vught, F.A. and de Weert, E. (eds) (1994). Higher Education Policy; An International Comparative Perspective, Oxford: Pergamon Press.

Goodsel, Ch.T. (1981). 'The new comparative administration: A proposal', International Journal of Public Administration 3, (2), 143-155.

Halls, W.D. (1977). 'Comparative studies in education: 1964-1977: A personal view', Comparative Education 13, (2).

Hancock, M.D. (1983). 'Comparative public policy: An assessment', in: A.W. Finifter (ed.), Political Science: The State of the Discipline, Washington D.C.: The American Political Science Association.

Heidenheimer, A.J., Hecclo, H. and Adams, C.T. (1990). Comparative Public Policy, the Politics of Social Choice in America, Europe and Japan, third edition, New York: St. Martin's Press.

Henderson, K.M. (1981). 'From comparative public administration to comparative public policy', International Review of Administrative Sciences 47, (4), 356-364.

Heper, M. (ed.) (1987). The State and Public Bureaucracies: A Comparative Perspective, Westport CT: Greenwood Press.

Jreisat, J.E. (1975). 'Synthesis and relevance in comparative public administration', Public Administration Review, 35, (6), 663-671.

Kaiser, F., Florax, R.J.G.M., Koelman, J.B.J. and van Vught, F.A. (1991). Public Expenditure on Higher Education, London: Jessica Kingsley Publishers. 
Kerr, C. (1978). 'Comparative effectiveness of systems: Unknown and mostly unknowable', in: C. Kerr, J. Millet, B. Clark, B. MacArthur and H. Bowen, 2 Systems of Higher Education: 6 Decisive Issues, New York: International Council for Educational Development.

Lane, J.E. (1990). 'Data archives as an instrument for comparative research', in: E. Oyen (ed), Comparative Methodology, Theory and Practice in International Social Research, London: Sage.

Leichter, H.M. (1979). A Comparative Approach to Policy Analysis, Cambridge: Cambridge University Press.

Levy, D. (1986). The State and Higher Education in Latin America: Private Challenges to Public Dominance, Chicago: University of Chicago Press.

Lijphart, A. (1975). 'The comparable-cases strategy in comparative research', Comparative Political Studies 8, (2), 158-177.

Maiworm, F., Steube, W. and Teichler, U. (1991). Learning in Europe: The ERASMUS Experience. London: Jessica Kingsley Publishers.

Mill, J.St. (1967) (orig. 1843). A System of Logic: Ratiocinative and Inductive, Toronto: University of Toronto Press.

Mitter, W. (1992). 'Comparative education', in: B.R. Clark and G. Neave (eds), The Encyclopedia of Higher Education 3, 1788-1797.

Morsy, Z. and Altbach, Ph.G. (eds) (1993). Higher Education in International Perspective: Towards the 21st Century, Paris and New York: UNESCO and Advent Books.

Neave, G. and van Vught, F.A. (eds) (1991). Prometheus Bound; The Changing Relationship between Government and Higher Education in Western Europe, Oxford: Pergamon Press.

Neave, G. and van Vught, F.A. (eds) (1994). Government and Higher Education Relationships across Three Continents; The Winds of Change, Oxford: Pergamon Press.

Niblett, W.R. and Freeman Butts, R. (eds) (1972). Universities Facing the Future, San Francisco: Jossey-Bass.

Noah. H.J. (1986). 'The use and abuse of comparative education', Comparative Education Review 28, (4), reprinted in: Ph.G. Altbach and G.P. Kelly (eds), New Approaches to Comparative Education, Chicago: The University of Chicago Press.

Nowak, St. (1989). 'Comparative studies and social theory', in: M.L. Kohn (ed.), Crossnational Research in Sociology, Newbury Park: Sage.

OECD (1991). Alternatives to Universities, Paris: OECD.

Opper, S., Teichler, U. and Carlson, J. (1990). Impacts of Study Abroad Programmes on Students and Graduates, London: Jessica Kingsley Publishers.

Oyen, E. (1990). 'The imperfection of comparisons', in: E. Oyen (ed.), Comparative Methodology, Theory and Practice of International Social Research, London: Sage.

Oyen, E. (ed.) (1990). Comparative Methodology, Theory and Practice in International Social Research, London: Sage.

Peters, B.G. (1988). Comparing Public Bureaucracies, Problems of Theory and Method, Tuscaloosa, AB: University of Alabama Press.

Przeworski A. and Teune, H. (1970). The Logic of Comparative Social Inquiry, New York: Wiley-Interscience.

Ragin, Ch.C. (1987). The Comparative Method, moving beyond qualitative and quantitative strategies, Berkeley: University of California Press.

Riggs, F.W. (1962). 'Trends in the comparative study of public administration', International Review of Administrative Sciences 28, (1), 9-15.

Riggs, F.W. (1991). 'Public administration: A comparativist framework', Public Administration Review 51 (6). 473-477.

Savage, P. (1976). 'Optimism and pessimism in comparative administration', Public Administration Review' 36, (4), 415-423.

Schench, E.K. (1990). 'The development of comparative research: Towards causal explanations', in: E. Oyen (ed.), Comparative Methodology, Theory and Practice in International Social Research, London: Sage.

Seabury, P. (ed.) (1975). Universities in the Western World, New York: Free Press. 
Sigelman, L. (1976). 'In search of comparative administration', Public Administration Review $36,(6), 621-625$.

Smelser, N.J. (1967). 'Notes on the methodology of comparative analysis of economic activity', in: Transactions of the Sixth World Congress of Sociology, vol. II, Evian, 96-119.

Smelser, N.J. (1976). Comparative Methods in the Social Sciences, Englewood Cliffs, N.J.: Prentice Hall.

Springer, J.F. (1976). 'Empirical theory and development administration: Prolognes and promise', Public Administration Review 36, (6), 636-641.

Swanson, G. (1971). 'Frameworks for comparative research: Structural anthropology and the theory of action', in: I. Vallier (ed.), Comparative Methods in Sociology: Essays on Trends and Applications, Berkeley: University of California Press.

Teichler, U. (1989). Changing Patterns of the Higher Education System, London: Jessica Kingsley Publishers.

Teune, H. (1990). 'Comparing countries: Lessons learned', in: Comparative Methodology, Theory and Practice in International Social Research, London: Sage.

Theisen, G., and Adams, D. (1990). 'Comparative education research, in: R. Murray Thomas (ed.), International Comparative Education, practices, issues and prospects, Oxford: Pergamon Press, pp. 277-301.

VSNU (1992). International Programme Review Electrical Engineering, Utrecht: VSNU.

van Vught, F.A. (ed.) (1989). Governmental Strategies and Innovation in Higher Education, London: Jessica Kingsley Publishers.

van Wart, M. and Cayer, N.J. (1990). 'Comparative public administration: Defunct, dispersed, or redefined?, Public Administration Review 50, (2), 238-248. 